\title{
O inconsciente segundo Ingmar Bergman
}

\author{
Lourival Belém Júnior*
}

\section{Resumo}

$\mathrm{O}$ autor propõe um paralelo entre filmes de Ingmar Bergman e duas obras de contistas russos (Tchekov e Tolstoi) como forma de compreender os conflitos psicológicos das personagens.

Palavras-chave: inconsciente, estudo comparativo, contistas russos.

Talvez a relação mais evidente que se possa estabelecer entre Ingmar Bergman e a Psicanálise esteja assentada no caráter purgativo que seus filmes exerceram para suas próprias angústias e obsessões - uma verdadeira auto-análise. A infância sexualmente reprimida, o medo de Deus e da morte, os sentimentos de culpa, os sonhos atormentados e sua extrema sensibilidade exigiram dele um longo processo de análise, o qual se efetivou em suas obras. Por diversas vezes, Bergman falou do surgimento de seus filmes, a partir de sonhos e medos, da satisfação de necessidades infantis e desejos inconscientes, com o próprio processo de filmagem, e de como pôde livrar-se de suas angústias, deixando-se levar pelas intuições que brotam das "profundezas obscuras". Assim, por exemplo, Morangos Silvestres seria uma espécie de inventário de sua vida passada. O Sétimo Selo o livraria do medo da morte. E Gritos $\boldsymbol{e}$ Sussurros representaria um acerto de contas com sua mãe, recriada a partir de quatro mulheres e suas neuroses. $\mathrm{Na}$ realidade, livrar-se-ia de uma idéia obsessiva aqui, para que ela reaparecesse, sob outra forma, mais adiante, em sua obra.

Numa anotação feita quando, em "quase hermética solidão", na ilha de Farö, trabalhava com o argumento de Gritos e Sussurros,

* Lourival Belém Júnior - Psiquiatra e Documentarista.

Comun. Inf., v. 5, n. 1/2, p.121-129, jan./dez. 2002 
Bergman fala de onde vem sua obra e do receio de transformá-la num caso clínico: "Creio que estou ficando maluco. Do sonho concreto e fluente que tive, estou passando a qualquer coisa semelhante, a uma triste descrição psicológica, sem valor nem emoção. Ora, isto não deve acontecer. E é isso que explica minha falta de disposição, a sensação de estar trabalhando em vão." $\mathrm{O}$ resultado final mostraria, depois, a mais perfeita elaboração de um estilo esmerado que se iniciara vinte e cinco anos antes.

Apesar de correr o risco de ser tomado inadequadamente por um caso clínico, segundo uma visão utilitarista da obra de arte, ou seja, o filme como exemplo didático de patologias, Gritos e Sussurros não autoriza qualquer incursão nesse sentido. Não há nele qualquer pretensão acadêmica de reduzir a complexidade da vida e dos sentimentos a uma naturalidade biopsicológica. O emaranhado de planos-mítico, religioso, político, ético-, muitas vezes quase indecifráveis, desautoriza uma leitura puramente psicológica, apesar de este ser um plano bastante desenvolvido.

A pertinência psicológica desse filme deve ser encontrada mais naquilo que é sugerido, subentendido, ou mesmo percebido-em contraste com outros planos - do que num possível desnovelamento de histórias pessoais. Estas existem, mas são incompletas e não conduzem a narração.

A sinopse. Agnes sofre com dores terríveis e encontra-se à beira da morte. Suas irmãs, Karin e Marie, e sua empregada Anna revezam-se para acompanhá-la na fase terminal de uma doença que já dura muitos anos. A longa agonia e o medo da morte despertam, em todas elas, fortes emoções e sentimentos. Velhos fantasmas, alguns guardados na memória dos personagens, outros trazidos ao público pelo narrador, reassumem seus postos naquela constelação onírica, expondo intensos conflitos de uma burguesia entediada e decadente.

As relações entre as irmãs, e entre elas e seus maridos, são marcadas por frieza e fingimento. Um simples toque pode desencadear reações de cólera reprimidas por contrato moral de convivência regulada. Num momento de desespero, numa tentativa de reconciliação das irmãs que acompanham a moribunda, as palavras somem por completo e restam o toque delicado das faces e o beijo como última possibilidade de carinho. Um olhar não esperado pode ameaçar a integridade do ego. Para extravasar suas angústias, o marido traído ten-

Comun. Inf., v. 5, n. 1/2, p.121-129, jan./dez. 2002 
ta o suicídio, a mulher-objeto mutila seus órgãos genitais antes de oferecer-se para a cópula matrimonial.

A casa onde as três irmãs se reencontram, durante o penoso fim de Agnes, funciona como uma metáfora de uma face do nosso mundo que não se mostra facilmente, e talvez devêssemos chamá-lo de mundo inconsciente. Salas, quartos e corredores com paredes vermelhas - a cor do interior da alma para Bergman - transformam-se em meandros escuros e labirínticos que guardam ressentimentos, ódios, culpas e desejos. Imagens recolhidas, ao longo dos anos, precipitam-se sobre a realidade quando as personagens femininas experimentam situações em que necessidades sociais e sentimentos profundos entram em conflito.

Em Bergman, a angústia jamais é desprovida de sentido, mesmo que não consigamos encontrá-lo num ponto determinado - um trauma específico que dá origem a um sintoma que resulta num crime, como nos filmes de Alfred Hitchcock. Apesar da densidade das cenas, da ambigüidade dos sentimentos, da evolução meio confusa do tempo e de um espaço que se altera sutilmente com a situação, podemos reconstruir, com Bergman, personagens coerentes, organicamente estruturados, com uma evolução temporal possível, dentro de um contexto compreensível. Trata-se de um cinema em que a intromissão do autor no mundo representado é uma constante - os símbolos artificiais misturam-se aos fatos, sem que o procedimento antinaturalista anule a carga emotiva e a verossimilhança do drama. Por vezes, as palavras perdem o significado habitual e os comportamentos não se permitem interpretar. Em qualquer caso, a expressão sempre rigorosa dos atores confere força e credibilidade impressionantes à narrativa. Ao término, ficamos menos com a impressão de um processo do que de um estado de coisa, talvez uma impressão de estados de almas atormentadas, procurando se mover e respirar sem culpa. Um drama em que a ação importa muito pouco, existindo mais em função de suas motivações ocultas. Bergman pára o tempo e revela instantâneos do espírito.

Misturam-se vivências que revelam as interações e o caráter de cada personagem, excepcionalmente elaborados quando se trata do universo feminino. Seqüências compostas de quadros isolados, de momentos plenos de significado, sobrepõem-se a fragmentos de descontinuidade espaço-temporal, numa tentativa de criar uma impressão de totalidade orgânica, em boa parte insondável, da alma humana. Com esses artifícios e discretíssimos movimentos de câmara, o cineas-

Comun. Inf., v. 5, n. 1/2, p.121-129, jan./dez. 2002 


\section{2}

ta consegue suficiente ilusão de realidade para imergir o espectador no mundo ficcional sem, contudo, deixar de lhe aplicar alguns choques que o despertem temporariamente para, logo em seguida, voltar a envolvê-lo com mais força no sonho que se desenvolve à sua frente. Um sonho realista que permite uma continuidade quase transparente entre os sonhos propriamente ditos e os momentos de vigília, ambos estruturados, de forma orgânica, em torno de uma racionalidade fílmica compreensível, bem diferente do sonho opaco à Luis Buñuel, sonho surreal, incompreensível, absurdo, que também representa o inconsciente, porém sem permitir significações concretas, percepção da organicidade do todo ou interpretações coerentes do mundo ficcional. Nesse sentido, Bergman usa o cinema para comunicar a natureza específica do sonho, em um processo de mimetização que não exclui a identificação do espectador com o mundo representado, fazendo-o experimentar a angústia das profundezas da alma; já Buñuel procura distanciar o espectador para que este possa conhecer o que há de absurdo e cínico nas relações pessoais e sociais, reveladas por meio de associações insólitas, deslocamentos e condensações, tal como trabalha nosso inconsciente e se estruturam nossos sonhos.

Há no filme uma seqüência que pode servir de paradigma da relação que faz o autor entre sonho e realidade. À noite, em seu quarto, Anna ouve um choro distante e sai à sua procura. Encontra Marie e Karin, que estão paralisadas, não ouvem e não vêem Anna, balbuciam sem emitir voz. O clima é de solidão e desespero. Há uma falta de sincronia sutil entre sons e imagens, forçando a busca de sentido em outro lugar. A mobília da casa, parecendo se organizar de acordo com a situação, aqui quase desaparece. Nesse pesadelo, Anna procura Agnes, que parece morta, mas ainda sofre, e uma lágrima escorre em seu rosto. Um pouco espantada, Anna ouve, de Agnes, palavras de quem ainda não se conformou com a morte. Anna lhe diz que é só um sonho e a outra responde que não, "pode ser para você, mas não para mim”. Não a vemos falar, a câmera permanece enquadrando a empregada, agora já um pouco menos aflita, ouvindo-a suplicar a ajuda das irmãs. Anna faz com que uma de cada vez entre no quarto; Karin diz que não a ama, sente-se enojada com aquela situação e não quer se envolver com a morte. Num clima cada vez mais tenso, chega a vez de Marie, que ainda tenta ajudar a irmã, porém o seu toque provoca-lhe um efeito devastador, deixando-a completamente aterrorizada, aprisionada naquela câmara mortuária, a debater-se violenta-

Comun. Inf., v. 5, n. 1/2, p.121-129, jan./dez. 2002 
mente num labirinto mental que, pouco a pouco, toma um ar mais realista. A consciência das hipocrisias que permeiam as relações humanas não impede a existência de alguns momentos fecundos em sua capacidade de horrorizar aqueles que se defrontam com situações de sofrimento terríveis. Assistimos, perplexos, aos últimos esforços da moribunda, já sob os cuidados ternos de Anna, que a deixa aliviada com o calor proporcionado pelo contato direto de seu corpo nu (cena do cartaz). A passagem do sonho para a realidade é imprecisa, gradual e não se realiza completamente; os dois estados mostram-se como aspectos da vida e se confundem. A seqüência, como todas as outras, mais ou menos realistas, vem emoldurada por planos aproximados do rosto da personagem principal - neste caso, Anna - os quais se fundem sob um tom avermelhado - teria sido um sonho da empregada?

Sentimos, nessa sequiência, que Deus parece não ter tido misericórdia da alma de Agnes, pois esta não conseguiu se despir das memórias dos longos e pesados sofrimentos que suportou na Terra. Certificamo-nos de que, mesmo com Ele, a vida não tem significado. Essa sequiência tem pequeno valor narrativo, porém grande valor simbólico. Parece-me a resposta do autor ao discurso de extrema-unção do pastor, quando reunido com a família enlutada junto ao leito da morta. Proferidas em seqüência anterior, as palavras do pastor expõem suas dúvidas (ou seriam as do próprio cineasta?) quando diz que Deus virou o rosto para Agnes. Lembra-se de que tinha com ela longas e exaustivas conversas e que a fé dela era mais forte que a sua própria. Ele admite que não sabe falar a língua que esse Deus compreende, mas que talvez ela o saiba.

Vemos um mundo que, pouco a pouco, desintegra-se em sonhos densos, angustiantes memórias, que tornam a vida um eterno ajuste de contas com um Deus sem misericórdia, impassível ante os sofrimentos de suas criaturas.

Os enquadramentos precisos, o movimento discreto da câmera, a sutileza dos gestos, a nuance das cores, a pontuação das cenas e a ilusão de realidade, que envolvem o espectador na ação quase congelada e o faz encarar uma vida de aparência natural, pegos num momento de excepcional reflexão sobre a morte e o sofrimento humano, é que garantem o tom amargo e desesperado das duas sequiências que narramos. Em suma, é a perfeita articulação entre o que se diz e o como se diz que nos permite sentir essas coisas quase impossíveis de serem ditas.

Comun. Inf., v. 5, n. 1/2, p.121-129, jan./dez. 2002 
Pode-se facilmente perceber como Bergman tratou todos os detalhes do seu filme. A direção de seus atores é segura, e os diálogos dão à obra uma naturalidade surpreendente; nada parece ficar sem o cuidado do diretor, que consegue criar um mundo, que se afasta da tela em nossa direção, à medida que nos exibe algumas faces de sua estrutura, esconde outras possivelmente inatingíveis, envolvendo-nos num universo que encanta e, em alguns momentos, até consegue confortar, como queria o cineasta - "Este filme será um filme para nos dar consolo. Se me for possível conseguir algo no gênero, sentirei um grande alívio. Do contrário, não vale a pena fazê-lo".

Num dos momentos mais comoventes do filme, Agnes chama Anna e reclama das dores insuportáveis que está sentindo. Anna é a única das três, que se revezam nos cuidados, capaz de cuidar da enferma sem repugnância e sem demonstrar medo. Naquela situação de desespero ante o sofrimento, em que parece não haver mais nada a ser feito, ela lhe oferece, com muita naturalidade, o próprio corpo, acariciandoa, beijando-a e confortando-a com o calor do seu seio.

As duas irmãs se esforçam para demonstrar carinho, mas o amor parece ter-se reduzido a mágoas e sentimentos de culpa. Não podem deixar Agnes morrer sozinha, mas também não conseguem esconder o espírito indisponível aos reclames afetivos do mundo exterior, venham eles dos seus maridos ou da irmã doente. A infância traumática, a educação austera, a mãe enigmática e a sexualidade reprimida se manifestam em seus comportamentos extremamente reservados e no clima de angústia que envolve toda a família. Numa seqüência em que as dores físicas chegam ao ápice, as irmãs, completamente apavoradas, compreendem sua impotência e vivem um suplício que se prolonga indefinidamente. A ajuda que oferecem é sempre desengonçada. O toque, quando existe, é frio e escrupuloso, bem diferente do desembaraço e da simplicidade de Anna, sempre disposta a socorrer com ternura a patroa debilitada.

Bergman sempre dedicou o melhor de sua criatividade ao universo feminino. Em entrevistas, dirá ele que Anna é uma nova personagem feminina que aparece em sua obra. Não por acaso, aparece num momento de sua carreira em que o diretor se dispõe a criticar, eficientemente, uma sociedade burguesa extremamente conservadora, punitiva, orientada por dogmas religiosos, em que o sexo era tabu e o comportamento, rigidamente disciplinado. Anna, que inferimos ter sido educada num universo diferente daquele, liderado pela mãe que mete

Comun. Inf., v. 5, n. 1/2, p.121-129, jan./dez. 2002 
medo às filhas, não desenvolve as neuroses das três irmãs e pode amar com uma naturalidade que a burguesia desconhece.

Freqüentemente, Gritos e Sussurros traz à lembrança dos cinéfilos As Três Irmãs, de Tchekhov. Certamente pelo fato de encontramos, nessas obras, três irmãs reunidas em casa, onde se sobressai o clima de desesperança e sofrimento, em meio à trivialidade do mundo burguês, provinciano e decadente. Mas enquanto na peça do escritor russo é o preconceito contra o trabalho que está na raiz da angústia e desintegração das identidades pessoais e sociais, no filme de Bergman a libido reprimida e as indagações metafísicas formam o substrato dos intensos conflitos morais e psicológicos.

Acredito, porém, que é com A Morte de Ivan Ilitch, de Leon Tolstoi, que poderíamos fazer um paralelo mais fecundo. Nessa obraprima da novelística russa, a iminência da morte permite a um juiz perceber a dimensão da indiferença social ao sofrimento humano. Ainda jovem, tendo conseguido uma razoável ascensão social, completamente de acordo com a decência burguesa - mãos limpas, camisas limpas, pouca bajulação, liberalismo moderado, vaidade discretamente perceptível, ambição no trabalho, casamento formal e uma casa com ar aristocrático, com uma pretensa originalidade que a fazia parecer uma perfeita imitação daquelas casas das pessoas de sua classe - deparase com uma doença incurável e a necessidade de uma inquietante peregrinação por consultórios de célebres especialistas. As longas esperas, o ar doutoral, o brilhantismo estéril - o juiz agora, com amarga consciência, pode perceber como as representações dos médicos são idênticas à farsa que ele próprio, um homem decente, interpretava diante dos acusados.

À sua família interessava saber quando descansaria; aos colegas, quando abriria uma vaga. Como no filme de Bergman, a única presença que o fazia se sentir melhor era a do camareiro Guerássim, um camponês que limpava sem nojo suas excreções, ajudava-o a manterse em posições antálgicas e o tratava com extrema cordialidade. Guerássim era o único que não precisava mentir.

Em estado de profunda solidão, sentindo dores insuportáveis, davase conta da monotonia da vida burocrática, do desprezo pelo sofrimento do outro, que à burocracia se associava, da hipocrisia do casamento, enfim, da crueldade dos homens e de Deus. Hipócrita agora era também a correção de sua vida. "Veio-lhe à mente que as suas veleidades quase imperceptíveis de luta contra aquilo que as pes-

Comun. Inf., v. 5, n. 1/2, p.121-129, jan./dez. 2002 
soas mais altamente colocadas consideravam correto, veleidades quase imperceptiveis que ele imediatamente repelia, podiam ser justamente as verdadeiras, e tudo o mais ser outra coisa. O seu trabalho, o arranjo da sua vida, a sua família, e esses interesses da sociedade e do serviço, tudo isto podia ser outra coisa. Tentou defender tudo isto perante si. E de repente sentiu toda a fraqueza daquilo que defendia. E não havia o que defender."

A consciência de que o mundo não passava dessa "outra coisa", a extrema-unção e três dias de dores irremediáveis ajudam a apaziguálo e a aceitar a morte. $\mathrm{O}$ tom neutro com que Tolstoi narra a vida de Ivan Ilitch acentua a ironia e a crítica social, enfoque privilegiado em sua obra. Em Bergman, confundem-se diversos planos da realidade, com destaque para os conflitos morais, religiosos e psicológicos; aqui a vida material, como produção e engrenagem social, perde em importância para as indagações metafísicas. Em ambos, contudo, a reserva de bondade do ser humano encontra-se fora do extrato burguês: Anna e Guerássim. Com eles, reencontramos o verdadeiro amor ao próximo. Os dois artistas procuram, como nos disse o cineasta, falando de si mesmo, "enfiar um prego na passividade e na indiferença das pessoas".

Tanto que, depois de haver cuidado de Agnes durante seus últimos 12 anos de vida, Anna é despedida sem qualquer consideração. É sinistra a discussão entre os dois casais sobre o que fazer com Anna, se deviam dar-lhe uma lembrança, dinheiro ou um novo trabalho. Concluem que ela é forte, jovem e teve uma vida fácil, devem-lhe uma lembrancinha, que já fora indevidamente prometida por Marie. Quando a empregada diz que não quer nada, cônscia da mesquinharia burguesa, o autoritário marido de Karim entende que ela está apenas querendo fazer um papel bonito, mas reafirma que não ganhará nada com isso. Ao se despedirem, Marie deixa uma cédula em sua mão, algo como uma gorjeta dada meio às escondidas. Marie esconde-se da irmã e do cunhado arrogante ou de si mesma? Afinal, seu gesto revela a frieza do afeto burguês, ao fazer equivaler o reconhecimento pelos doze anos de terna dedicação àquele dinheiro secreto. Anna quis, entretanto, como lembrança, aquilo que mais lhe importava-o diário de Agnes. Nele estavam guardados o sofrimento e os instantes de felicidade de uma criatura humana. Anna podia ouvir o que ele dizia, estava disponível para aquelas palavras ainda sensíveis - a mulher humilhada, a mãe que perdera a filha criança conforta-se com suas preces e o

Comun. Inf., v. 5, n. 1/2, p.121-129, jan./dez. 2002 
diário de Agnes, que transmite uma tênue alegria de viver. As irmãs continuam amarguradas e não conseguem se reconciliar, agindo como força de destruição.

\section{Abstract}

The author proposes a parallet between Ingmar Bergman's movie Gritos $e$ sussuros and Tchekov's As três irmâs and Tolstoi's A morte de Ivan Ilitch in order to better understand the character's psychological conflits.

Keywords: unconsciousness, comparative study, Russian writers.

\section{Referências}

BERGMAN, Ingmar. Imagens. São Paulo: Martins Fontes, 1996.

BJORKMAN, Stig.; MANNS, Torsten.; SIMA, Jonas. O cinema segundo Bergman. Rio de Janeiro: Paz e Terra, 1977.

TCHEKHOV, Anton. As três irmãs. São Paulo: Editor Victor Civita, 1979.

TOLSTOI, Leon. A morte de Ivan Ilitch e Os três anciãos. Rio de Janeiro: Ediouro, 1997.

Comun. Inf., v. 5, n. 1/2, p.121-129, jan./dez. 2002 